\title{
ALIMENTAÇÃO INFANTIL E O MARKETING DA INDÚSTRIA DE ALIMENTOS. BRASIL, 1960-1988
}

\author{
Infantile feeding and the food industry marketing. \\ Brazil, 1960-1988
}

\author{
Suely Teresinha Schmidt Passos de Amorim*
}

\section{RESUMO}

Este estudo trata das mudanças na alimentação infantil no Brasil, de 1960 a 1988, por meio da análise da publicidade comercial veiculada em revistas femininas de grande circulação no período. Trata-se de um estudo interdisciplinar, centrado na área da História da Alimentação. A metodologia empregada versou sobre a análise do discurso, representado nesta pesquisa pelas mensagens e imagens publicitárias de alimentos para crianças. O estudo evidencia que o principal fator responsável pelas mudanças na alimentação infantil, especialmente pela introdução do leite em pó como substituto do leite materno e de outros alimentos que complementaram o aleitamento, foi a indústria de alimentos.

Palavras-chave: alimentação infantil, marketing, discurso médico.

\begin{abstract}
The present work aims at investigating infants' eating habits from 1960 to 1988, in Brazil, through an analysis that focuses on commercial advertisements published in wide circulation women magazines in Brazil. It consists of an interdisciplinary study, in the area of Food History. The methodology adopted centered on the discourse analysis in advertising messages and pictures of children's food. This study assumes the premise that the food industry marketing fostered the dissemination of artificial suckling, using dried milk, depriving infants from breast feeding, and, at the same time, allowing for the emergence of other supplementary products that favored early weaning.
\end{abstract}

Key-words: infant feeding, marketing, medical discourse.

* Doutora em História pela Universidade Federal do Paraná. Professora Adjunto do Departamento de Nutrição-UFPR. 


\section{Introdução}

O presente estudo trata das práticas e hábitos alimentares infantis no período de 1960 a 1988, no Brasil, por meio da análise das peças publicitárias de alimentos para crianças de zero a dois anos, publicadas em revistas femininas de grande circulação no período. Este estudo insere-se na História da Alimentação, um tema que tem despertado crescente interesse entre os historiadores.

Diversos autores concordam que, para os historiadores, a alimentação é vista como "estratégica no sistema de vida e de valores das diversas sociedades", 1 o que aponta para a necessidade de estudos interdisciplinares. Para Antunes dos Santos, a integração com outras áreas do conhecimento permite abordar a questão da alimentação de uma forma ampla, sem "contrapor temas históricos diversos, mas sim em confrontar modos diversos de fazer História com outras Ciências Sociais, com a Arte e a Literatura, sem que a História perca sua identidade, mas que possa captar a riqueza trazida pelas referências conceituais mais diversificadas". ${ }^{2}$ Desse modo, como a História da Alimentação, também os hábitos e práticas alimentares infantis podem ser investigados sob o olhar de diferentes áreas do conhecimento, permitindo uma abordagem interdisciplinar.

Tendo em vista que a alimentação infantil sofreu mudanças no período compreendido entre1960 e 1988, evidencia-se que o principal fator responsável por essas mudanças, especialmente, pela introdução do leite em pó como substituto do leite materno e de outros alimentos que complementaram o aleitamento, foi a indústria de alimentos.

As principais fontes utilizadas neste estudo foram as impressas e provenientes de revistas femininas de grande circulação no período, como Cláudia e Pais e Filhos. Dessas revistas, foram selecionadas as propagandas de alimentos que eram dirigidas às mães, com apelos orientados para a saúde, nutrição, crescimento e desenvolvimento de seus filhos. Para complementar as informações transmitidas para o grande público foi também utilizada a revista O Cruzeiro, especialmente os periódicos publicados no final da década de 50 e início da de 60 .

\footnotetext{
1 FLANDRIN, J. L.; MONTANARI, M. História da alimentação. São Paulo: Estação Liberdade, 1996. p. 22.

2 SANTOS, C. R. A. dos. Por uma história da alimentação. História: Questões \& Debates, Curitiba, ano 14, n. 26-27, p. 156, 1997.
} 
A baliza inicial espaço-temporal - 1960 - está vinculada ao final do governo Juscelino Kubitschek, período em que a economia, liderada pelo setor industrial, cresceu em termos relativos e absolutos. Entre os diversos setores industriais expandidos e modernizados, como os de energia, transportes e indústria de base, inclui-se também o setor de alimentação.

Com a consolidação do desenvolvimento industrial, a indústria de alimentos, particularmente a indústria de leite em pó destinado à alimentação de lactentes, caracterizou-se por uma grande expansão, favorecida pela entrada do marketing como ferramenta de promoção e venda de seus produtos. Estratégias de marketing foram utilizadas tanto para promover esses produtos entre o público em geral, como para sensibilizar e convencer os profissionais da área da saúde de que poderiam indicar e prescrever alimentos industrializados para as crianças desde o nascimento destas, com absoluta segurança. A partir desse período - de 1960 até o início da década de 80 -, dá-se a expansão do aleitamento artificial em substituição ao aleitamento materno, graças a vários determinantes e, entre eles, o poder econômico da indústria de leite em pó.

Essas estratégias intensificaram-se até o final da década de 70, quando, então, organismos internacionais, como a Organização Mundial da Saúde OMS - e o Fundo das Nações Unidas para a Infância - Unicef -, realizaram, em Genebra, uma Reunião Conjunta sobre a Alimentação de Lactentes e Crianças na Primeira Infância, expressando a necessidade de que os governos nacionais e a sociedade, em geral, tomassem medidas urgentes no sentido de promover a saúde e a nutrição infantil, tendo como recomendação principal o apoio e o incentivo ao aleitamento materno. Em 1981, esses mesmos organismos criaram o Código Internacional do Marketing de Substitutos do Leite Materno, que o Brasil traduziu em normas, em 1988. Também em 1981, o Ministério da Saúde implantou o Programa Nacional de Incentivo ao Aleitamento Materno (PNIAM), com várias estratégias de ação na área da educação, saúde, controle estatal da propaganda de alimentos infantis e respeito a leis de proteção à nutriz, entre outras.

No ano de 1988, baliza final do período deste estudo, foi aprovada pelo Conselho Nacional de Saúde e homologada por meio de portaria ministerial a Norma Brasileira de Comercialização de Alimentos para Lactentes, documento que restringiu a ação do marketing da indústria de leite em pó.

O método utilizado no presente estudo foi a análise do discurso, entendendo que este está contido no documento histórico, representado nesta pesquisa pelas mensagens e imagens publicitárias de alimentos para crianças, publicadas nas referidas revistas, durante o período selecionado para este 
estudo. Ao considerar as mensagens publicitárias sobre alimentação infantil como discursos e fontes ou documentos históricos para fundamentar esta pesquisa, entende-se que esse material só pode ser analisado quando inserido no contexto em que foi produzido.

$\mathrm{Na}$ análise de um documento, é preciso considerar não apenas o que está explícito no discurso, mas o que está subentendido, ou seja, a subjetividade do conteúdo. Além disso, é importante evidenciar não apenas os argumentos e razões colocados pelo autor, mas especialmente suas intenções e as ambigüidades contidas no texto. ${ }^{3}$ Desse modo, nas peças publicitárias analisadas, verifica-se que as intenções do anunciante nem sempre eram expostas de modo claro, e tanto o texto das mensagens quanto as imagens despertavam o imaginário do leitor, transportando-o para situações distantes de seu cotidiano.

\section{O discurso publicitário referente aos alimentos infantis}

O desenvolvimento da indústria de leite em pó, no período posterior à Segunda Guerra, até a década de 80 , colocou à disposição da população a abundância de seus produtos, divulgando-os por meio de diversas estratégias de marketing. Essa produção foi contabilizada no PIB brasileiro e traduzida como contribuição econômica ao crescimento nacional.

Ao longo desse período, o progresso técnico foi intenso e o discurso publicitário da maior empresa fabricante de leite em pó - a Nestlé -, enfocava o grande benefício social que prestava ao país ao contribuir para a redução das taxas de mortalidade infantil. Mas, algumas décadas mais tarde, foi possível identificar o "outro lado da moeda", ou seja, os prejuízos causados especialmente às populações infantis mais pobres do planeta, que deixaram de ser amamentadas para receber mamadeiras com leite em pó.

A contaminação dessas mamadeiras e bicos, pela falta total ou parcial de água potável necessária para sua higienização, causou gravíssimos problemas às crianças do Terceiro Mundo. ${ }^{4} \mathrm{~A}$ diluição excessiva do leite em pó, realizada pelas camadas mais pobres da população, na tentativa de economizar o conteúdo da lata para conseguir maior número de mamadas,

3 ALVES, Paulo. Perspectivas acerca do método e técnica de análise dos discursos. História, São Paulo, v. 2, p. 33-37, 1983.

4 MARQUES, M. B. Discursos médicos sobre seres frágeis. Rio de Janeiro: Fiocruz, 2000. 
foi outro problema encontrado e que ainda ocorre nos dias atuais. O preparo inadequado do leite, especialmente quando diluído numa quantidade maior de água do que a recomendada, não atende às necessidades nutricionais da criança, trazendo possíveis prejuízos ao seu crescimento e desenvolvimento, debilitando o organismo e favorecendo o surgimento de infecções e outras enfermidades.

Esses prejuízos causados à nutrição e saúde infantis, em grande parte atribuídos à indústria de leite em pó, foram divulgados a partir do final da década de 70 e início da de 80 , por organizações internacionais e nacionais, ao verificarem os altos índices de desnutrição e mortalidade infantis que assolavam extensas regiões do Terceiro Mundo, nelas incluindo-se o Brasil. Até então, a indústria cresceu ao produzir, modificar e lançar no mercado novos produtos cada vez mais sofisticados, com o objetivo de "atender às necessidades" de seu público consumidor. Todos os recursos de marketing, entre eles a mídia, foram utilizados nesse processo, com a finalidade de sensibilizar as mulheres para a prática do aleitamento artificial e, conseqüentemente, para o consumo do leite maternizado e outros produtos de desmame. ${ }^{5}$

\section{Leite para lactentes: o papel da Nestlé}

Com a fabricação do leite condensado no final do século XIX, na Suíça, a indústria de lacticínios conseguiu um desenvolvimento tecnológico que marcou, no início do século XX, uma profusão de oferta de leites em pó e fórmulas lácteas. ${ }^{6}$

A Companhia Industrial e Comercial Brasileira de Produtos Alimentares - Nestlé -, por ter sido a primeira empresa multinacional de produção de leite em pó, instalada no Brasil, em 1921, dominou o mercado de leite em pó e de outros alimentos que complementaram a alimentação infantil, de 1960 a 1988.

5 Leite maternizado foi a denominação dada pela indústria ao leite em pó com a composição química mais próxima do leite materno, com o objetivo de substituí-lo. Posteriomente, essa denominação foi substituída por "leite em pó modificado", em virtude da publicação do "Código Internacional de Comercialização de Substitutos do Aleitamento Materno", pela OMS/Unicef, em 1979 e, em 1988, pela "Norma Brasileira de Comercialização de Alimentos para Lactentes".

6 SOUZA, L. M. B. M.; ALMEIDA, J. A. G. História da alimentação do lactente no Brasil: do leite fraco à biologia da excepcionalidade. Rio de Janeiro: Revinter, 2005. 
Até então, os leites industrializados eram importados e, por isso, seu consumo dava-se especialmente pelas classes sociais de maior poder aquisitivo.

As peças publicitárias encontradas e analisadas nas fontes selecionadas mostram a hegemonia dessa empresa que tem evoluído ao longo do tempo. Suas propagandas acompanharam o momento político e cultural do país e foram dirigidas ao consumidor direto - a população em geral - e aos profissionais de saúde.

Os principais alvos do marketing da indústria de alimentos infantis, particularmente da Nestlé, no Brasil, especialmente os destinados à criança durante o seu primeiro ano de vida, foram os profissionais de saúde e as mães. Entre a indústria e os médicos estabeleceu-se uma reciprocidade de interesses: enquanto para a primeira interessava a expansão do mercado e os lucros auferidos, para os médicos interessava manter o poder do conhecimento sobre a técnica no preparo das fórmulas lácteas, o que era desconhecido pelas pessoas leigas, como mães, parteiras e curandeiras. Essa forma de poder foi aceita e se manteve porque, como lembra Foucault, não se apresenta como uma força negativa, que diz não, mas sim como um poder que produz saber, que produz discurso. ${ }^{7}$ E o discurso da empresa atingiu os segmentos da população que correspondiam aos seus interesses: mães, médicos e outros profissionais de saúde.

Em 1928, a Nestlé lançou, no Brasil, o Lactogeno, um produto que se caracterizou por ser o primeiro leite modificado para lactentes. Esse alimento foi obtido a partir do leite integral e teve sua composição nutricional modificada para aproximar-se das características do leite materno, com o objetivo de atender às exigências do organismo do bebê. Foi também chamado de "maternizado", numa clara alusão de semelhança ao leite materno. A partir dessa data, outras marcas foram ofertadas ${ }^{8}$ e divulgadas pela imprensa.

Nesse período, os médicos, embora acreditassem que o leite em pó constituía um avanço, incentivavam a mulher a amamentar. Entretanto, na impossibilidade de a mãe alimentar, não faziam restrições ao uso do leite em pó, a não ser ao seu preço, que era considerado elevado para boa parte da população.

7 FOUCAULT, M. Microfisica do poder. 8. ed. São Paulo: Loyola, 1989.

8 De acordo com informações do Serviço Nestlé ao Consumidor, os leites em pó modificados para lactentes foram lançados na seguinte ordem cronológica: Lactogeno, em 1928; Eledon e Nestogeno, em 1933; Pelargon, em 1949; Prodieton, em 1959; Semilko, em 1961 e Nanon, em 1969. 
Uma das estratégias de marketing muito utilizada nesse período pelas empresas em geral, foi o lançamento de peças publicitárias, tendo como tema datas comemorativas. Um exemplo, foi a comemoração do Dia da Criança, o qual foi instituído oficialmente em 12 de outubro de 1924, associado à comemoração da Descoberta da América. Nos discursos institucionais da época, a criança foi monumentalizada, numa tentativa de educar física, intelectual e moralmente o cidadão do futuro. A exaltação da criança tinha como objetivo construir um país viável, com possibilidade de progresso, ou seja, a infância foi projetada como "utopia de um novo mundo adulto a ser estabelecido."

Ao completar 40 anos de instalação de sua primeira fábrica no Brasil, a Nestlé publicou uma propaganda em quatro páginas, com o título: "Nestlé 1921:1961 Quarenta anos a serviço da família brasileira", ${ }^{10}$ com vários desenhos ilustrativos em que procurava passar uma imagem de empresa cuja principal preocupação era produzir alimentos considerados por ela mesma como sinônimo de qualidade, saudáveis e nutritivos para todas as faixas etárias e, em especial, para a criança desde seu nascimento. Por isso, afirmava que, para as mães, o nome Nestlé "é algo mais: representa a garantia de uma alimentação pura e substanciosa, adequada a assegurar a saúde e o bom desenvolvimento dos filhos".

Com uma agressiva estratégia de marketing, a Nestlé disseminou a cultura dos leites industrializados e fórmulas para lactentes, tendo como parceira a corporação médica na valorização do aleitamento artificial. Eram freqüentes, nas peças publicitárias da época, imagens de médicos ao lado de famílias que aparentavam saúde, beleza e felicidade.

A empresa também procurava propagar uma imagem de promotora do desenvolvimento nacional e afirmar seu compromisso com a questão social, pois, segundo a mesma mensagem publicitária, "recolhe aos cofres públicos elevados tributos fiscais, que redundam em benefício da coletividade". A Nestlé divulgava também seu estímulo às atividades produtivas do país, ao garantir "aos fazendeiros colocação certa do leite produzido" e adquirir grandes quantidades de produtos, como açúcar, cacau, folhas-de-flandres, madeira e papel da indústria nacional, beneficiando-as. Dessa maneira, deixava implícito na mensagem a contribuição feita à política nacional-desenvolvimentista do governo de Juscelino Kubitschek, que "combinava o Estado, a empresa

9 VEIGA, C. G.; GOUVEA, C. S. Comemorar a infância, celebrar qual criança? Festejos comemorativos nas primeiras décadas republicanas. Educação e Pesquisa, São Paulo, v. 26, n. 1, p. 140, 2000. 10 O CRUZEIRO, p. 45-48, 5 ago. 1961. 
privada nacional e o capital estrangeiro para promover o desenvolvimento, com ênfase na industrialização". ${ }^{11}$ A Nestlé também se colocava como a principal responsável pela diminuição dos índices de mortalidade infantil, ao afirmar que:

\begin{abstract}
...de acordo com o Serviço de Divulgação e Estatísticas do Departamento Nacional da Criança, depois do lançamento dos alimentos especiais para crianças, houve sensível redução da mortalidade infantil. Orgulhamo-nos de ter participado desta grande vitória, com os nossos produtos da linha dietética. ${ }^{12}$
\end{abstract}

Quando a Nestlé instalou sua primeira fábrica em território nacional, em 1921, o Brasil não dispunha de estatísticas sobre a mortalidade infantil, porém, de 1960 a 1961 , a média nacional era de 120 por mil. ${ }^{13}$ Embora tenha havido uma redução da mortalidade infantil no Brasil, nesse período de 40 anos, a taxa poderia ainda ser considerada muito alta e, em regiões de extrema pobreza, esses valores eram três vezes superiores à média nacional.

Assim, é difícil aceitar que a Nestlé tenha contribuído para a redução dos índices de mortalidade infantil por vários motivos: o leite em pó, embora com valores nutricionais aproximados ao do leite materno, não contém imunoglobulinas responsáveis pela defesa do organismo infantil, como o leite humano; as condições de saneamento, na maior parte das regiões brasileiras, eram muito precárias e, desse modo, a água utilizada para a diluição do leite em pó poderia ser um veículo de contaminação, tanto no preparo das mamadeiras como na higienização dos utensílios; como já mencionado, o custo de uma lata de leite poderia induzir as mães de baixa renda a diluírem excessivamente o leite em pó, tornando-o insuficiente em quantidade de energia e nutrientes.

As condições características de regiões subdesenvolvidas, como a falta de saneamento, ou seja, de água tratada e de rede de esgotos, a dificuldade de acesso aos serviços básicos de saúde, a falta de higiene na manipulação e preparo dos alimentos, inclusive do leite de vaca, estiveram entre os principais fatores que levaram à morte milhares de crianças em idades precoces.

11 FAUSTO, B. História do Brasil. 8. ed. São Paulo: Edusp, 2000. p. 427.

12 O CRUZEIRO, p. 45-48, 5 ago. 1961.

13 Dado publicado na revista Veja, de 29 de outubro de 1986, na reportagem "Um sopro de vida", em que mostra dados da pesquisa IBGE/Unicef sobre mortalidade infantil no Brasil. Cf. VEJA, 29 out. 1986, p. 102-103. 
No Brasil, a qualidade do leite foi motivo de reportagens na revista $O$ Cruzeiro: a primeira, em 1958, "Leite do Rio leva morte a domicílio", ${ }^{14}$ descreve as péssimas condições higiênicas durante a ordenha, a precária situação de saúde dos rebanhos, a pobreza dos pastos e denuncia que "a morte começa cedo. Setenta por cento das crianças que desaparecem no Distrito Federal são vitimadas pela impureza do leite". Mais tarde, em 1962, o problema continuou, e a revista publica: "Leite, escândalo engarrafado", ${ }^{15}$ argumentando que $70 \%$ das crianças paulistas morrem por infecções intestinais. "É o veneno que usinas sem escrúpulos entregam ao povo. Ao ingeri-lo, o menino está se expondo à morte, pois o que bebe é uma verdadeira cultura de bactérias". Embora em tom sensacionalista, as reportagens revelavam a importância da qualidade do leite no índice de morbidade e mortalidade de crianças, problema já solucionado, no início do século, em países desenvolvidos.

Se as medidas de saneamento e higiene não chegaram aos países subdesenvolvidos, a mesma coisa não ocorreu com a expansão do mercado de leite em pó, principalmente as fórmulas para lactentes, que foram disseminadas pelo mundo todo. ${ }^{16}$ Ao contrário do que apregoava a Nestlé, em seu anúncio comemorativo aos 40 anos de instalação no Brasil, de acordo com Marques,

...o risco da mortalidade de crianças que são alimentadas artificialmente, em regiões muito pobres, onde persistem os problemas de acesso à água potável, saneamento básico, é duas ou três vezes maior do que o daquelas que são aleitadas ao seio. ${ }^{17}$

Mesmo utilizando-se das vantagens da divulgação da péssima qualidade do leite de vaca, para propagar a qualidade higiênica e nutricional do leite em pó, a morbidade e mortalidade infantis continuavam altas, em razão das condições miseráveis em que vivia grande parte das crianças brasileiras.

A sensibilização dos profissionais de saúde para a indicação do leite em pó para os lactentes destaca-se como uma importante estratégia de marketing, utilizada pela indústria, na promoção de seus produtos. Para isso, a Nestlé lançou mão de diversas tácticas, como: o estímulo a produções acadêmicas,

14 O CRUZEIRO, p. 132-138, 13 set. 1958

15 O CRUZEIRO, p. 55,28 jul. 1962.

16 Só no Brasil, a Nestlé expandiu de tal forma seu mercado que, em 1958, portanto 37 anos depois da instalação de sua primeira fábrica em Araras, São Paulo, já havia instalado mais quatro fábricas: Barra Mansa, Araraquara, Porto Alegre e Três Corações.

17 MARQUES, op. cit. 
premiando os melhores trabalhos na área de Puericultura e Pediatria; a divulgação de estudos por meio do Serviço de Informação Científica, criado em 1956, juntamente com o primeiro Curso Nestlé de Atualização em Pediatria; a distribuição de amostras de produtos para os pediatras, acompanhados de folhetos explicativos e orientações sobre a composição química dos alimentos; o patrocínio de eventos científicos, até financiando a participação de profissionais, entre outras iniciativas. Com esse tipo de estratégia, a Nestlé procurou influenciar a formação de profissionais de saúde, especialmente dos pediatras, com o objetivo de que o produto chegasse aos consumidores com o aval médico. Desde 1930, as propagandas de leite em pó incorporaram a figura do médico como avalista do produto, associando-o à ciência. Como uma autoridade do saber, respeitada pela população, o médico era o intermediário ideal entre a indústria e o público consumidor.

Durante décadas, particularmente entre 1940 e 1970, a Nestlé construiu elementos culturais para valorizar o leite em pó e encarregou-se de disseminálos na sociedade brasileira por meio dos pediatras, ou seja, dos profissionais que detinham o poder de prescrever a dieta da criança nos primeiros meses de vida. $\mathrm{O}$ avanço científico em relação às peculiaridades do metabolismo infantil e conseqüentes necessidades nutricionais levou à formulação de novos produtos, os quais foram lançados no mercado e difundidos entre a população. Dessa maneira, a indústria utilizou a ciência da nutrição para criar abordagens e retóricas no sentido de divulgar e comercializar seus produtos..$^{18}$

As peças publicitárias publicadas nas revistas, fontes para este estudo, trazem imagens de bebês robustos, geralmente loiros de olhos claros, em meio a latas de leite, em situações muito agradáveis e de tranqüilidade, sorridentes, em contato com a natureza ou nos braços de mães bem vestidas, alegres e despreocupadas, com todo o tempo disponível para o seu filho. Cada quadro construído com muito cuidado estimula a transposição do cotidiano e o desejo do receptor da mensagem, de viver uma situação idêntica. Como explica Baudrillard, é o discurso da felicidade como referência absoluta do consumo. ${ }^{19}$

Nas peças publicitárias aparecem várias marcas de leite em pó para lactentes, ressaltando que ao médico cabe a indicação da marca mais apropriada para cada criança. Algumas mensagens afirmam que cada bebê tem características próprias que o médico irá identificar e, com base nessa 
informação, receitar a marca de leite em pó modificado que melhor se adapte a essas características. O texto não menciona se são características orgânicas, emocionais ou psicológicas, e os rótulos das diferentes marcas também não mencionam para qual delas o leite ali contido se destina. Ao identificar a criança como "única no mundo", o texto publicitário personaliza o bebê, sugerindo a personalização do leite a ser empregado em sua alimentação. Embora o produto seja o mesmo (leite modificado), as marcas são diferentes para que a mãe tenha a expectativa da escolha ou da indicação, pelo médico, de um leite específico para seu filho. A escolha, como afirma Baudrillard, ${ }^{20}$ é proporcionada ao consumidor como signo de liberdade. Ao sugerir à mãe que busque o aval do médico para a decisão sobre a melhor marca de leite para seu fillho, a empresa, ao mesmo tempo em que apresenta à mãe a possibilidade de escolha e, dessa maneira, oportuniza a "personalização", transfere para o profissional essa responsabilidade e, assim, aumenta a confiança no produto.

Outra peça publicitária apresenta as mesmas marcas de leite para lactentes, com a apresentação dos novos rótulos, os quais trazem a gravura de uma mãe com seu bebê. Com a frase de anúncio "Olhe mamãe:nós dois estamos nos novos rótulos", ${ }^{21}$ o discurso explora a relação mãe-fillho, associando a imagem de carinho aos leites Nestlé especiais para bebês e, desse modo, incorporando o leite em pó às práticas maternas. $\mathrm{O}$ binômio mãe-filho e o sentimento de ternura foram bastante explorados como uma das vantagens do aleitamento materno em outras publicações, dirigidas às mães, sobre alimentação infantil. Nessa peça publicitária, são considerados sinônimos do produto divulgado, ou seja, sentimentos são associados ao leite em pó.

Nas propagandas sobre os leites modificados, a referência ao leite materno - quando ocorre - é feita para mencionar sua falta e, por isso, aponta para a necessidade de sua substituição por "um leite especialmente adaptado ao organismo infantil, um leite que o faça forte e sadio". ${ }^{22}$ Essa mensagem aparece numa peça publicitária, na qual é mostrada uma mamadeira com a inscrição "Na falta de leite materno, Nestlé tem o leite certo", divulgando seus leites modificados. A ousadia desse anúncio revela-se na naturalidade como trata a falta de leite materno, como se fosse algo que acontecesse com freqüência.

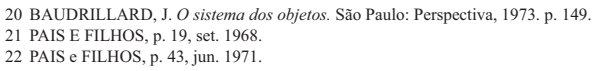


As expressões “força e saúde”, também destacadas na mensagem, eram uma constante em discursos publicitários cujo teor se voltava para o futuro, incluindo-se o futuro da nação. Esse foi um momento da história nacional, no qual o futuro do país, representado pelas crianças, foi muito enfatizado pelos governantes. Também por isso, a importância de que fossem fortes e sadias. Embora o arrocho salarial deixasse a classe trabalhadora cada vez mais pobre, a pobreza, a miséria e a questão do menor abandonado não estavam expostas na publicidade comercial, a qual, deveria estar em sintonia com a propaganda oficial.

Mesmo produzindo leites modificados para lactentes, a Nestlé utilizava também suas estratégias de marketing para divulgar o leite integral Ninho, para bebês. Esse leite foi criado pela Nestlé, em 1944, com uma embalagem cor de caramelo. Em 1965, foi lançado o Ninho Integral Instantâneo, com a embalagem atual: amarela, com o nome do produto escrito em letras verdes. Em todas as propagandas do produto veiculadas nesse período, não aparece a expressão "leite em pó", apenas "Leite Ninho", o que caracteriza uma estratégia de marketing e leva à substituição da denominação do produto pela marca, a ponto de o consumidor associar leite (em pó) a Ninho. A marca acaba construindo uma passagem do realismo da matéria - identificado pelo nome comum -, ao simbolismo, caracterizado pelo nome próprio. ${ }^{23}$

Diversos anúncios em revistas femininas exploraram o mesmo tema "Fique em paz com sua consciência. Exija leite Ninho" e "Saúde, felicidade e leite Ninho". As imagens mostram bebês segurando um copo de leite na mão, engatinhando, dando os primeiros passos, com a mãe tentando colocálos em uma árvore, junto a crianças maiores, ou seja, sem fazer qualquer menção explícita, sugerem que o leite em pó integral destina-se a bebês de uma faixa etária maior, pois para os primeiros meses de vida existem os leites modificados. Em algumas delas, o que varia é apenas a imagem, numa tentativa de evidenciar que crianças que tomam leite Ninho são sempre crianças saudáveis e felizes. As imagens agregam ao produto não só situações agradáveis de vida, em que crianças brincam, alegres e em contato com a natureza, como também saúde e felicidade.

De maneira implícita, os textos lembram a alimentação da criança nos primeiros meses de vida, ao afirmarem: "a proteção que você vem dando aos seus filhos desde o nascimento deve continuar". ${ }^{24}$ Essa proteção, a que se

23 CARVAlHO, N. Publicidade: a linguagem da sedução. 2. ed. São Paulo: Ática, 1998.

24 PAIS e FILHOS, p. 53, fev. 1971. 
refere a propaganda, faz alusão à alimentação com leites em pó modificados Nestlé e que, agora, deve continuar com o leite Ninho e outros produtos já incorporados na alimentação de seus irmãos maiores.

Quando o regime militar, por meio da Assessoria Especial de Relações Públicas - Aerp -, procurava, pela propaganda oficial, divulgar o otimismo, assim como valores que desejaria ver realizados na sociedade brasileira, ${ }^{25}$ a publicidade comercial evidenciou, em suas mensagens, cenas de vida que estavam sintonizadas com esses ideais. Em imagens de anúncios do leite Ninho, identificam-se situações que despertam no receptor o desejo de vivê-las em seu cotidiano. Desde o movimento higienista, passou-se a considerar que o amor de mãe se manifesta pela atenção e cuidado que ela dedica a seus filhos e, entre esses cuidados, a alimentação - que se inicia com o aleitamento materno - foi considerada fundamental. A responsabilidade da mãe em criar filhos sadios, bem alimentados e educados, que está sempre atenta e disponível, traduz o papel da mulher, aprovado pela sociedade, evocado pelo discurso médico e reforçado pelas instituições governamentais.

As imagens de mães felizes, que aparecem nas peças publicitárias brincando com seus filhos saudáveis ou abraçando-os, transformam uma relação pessoal em uma relação social. Na concepção da Aerp, é com base em uma família bem estruturada, alicerçada em valores morais e sentimentos nobres que se constrói uma sociedade com comportamentos adequados.

Percebe-se, em todas essas mensagens, o que Piratininga definiu como o "benefício da filiação", ou seja, uma estratégia de publicidade que, utilizando temas como crianças, animais, demonstrações de sentimentos como amor e afeto, leva as pessoas a se afiliarem a uma determinada "marca" pelo engajamento de suas emoções. ${ }^{26}$

Se a leitora não identificava sua vida àquela retratada nos anúncios publicitários em que aparecem mães e filhos felizes e em harmonia, a falha estava em sua incapacidade para cumprir o papel que a família e a sociedade dela esperavam. Problemas que, muitas vezes, são determinados socialmente, assumem uma dimensão particular e individual, e a tendência é um movimento em direção ao consumo do produto que se anuncia como capaz de transformar o seu cotidiano na imagem idealizada. ${ }^{27}$

25 Para mais detalhes, ver: FICO, C. Reinventando o otimismo: ditadura, propaganda e imaginário social no Brasil. Rio de Janeiro: Fundação Getúlio Vargas, 1997.

26 PIRATININGA, L. C de Publicidade: arte ou artifício? São Paulo: T. A. Queiróz, 1994.

27 VESTERGAARD, T.; SCHRODER, K. A linguagem da propaganda. São Paulo: Martins Fontes, 1988 
As mensagens com a frase tema repetem-se em diferentes peças publicitárias, como em diferentes períodos de tempo: em algumas muda apenas o cenário, ou seja, a imagem. "Exija leite Ninho e fique em paz com sua consciência" é uma frase atemporal aparecendo nas propagandas do produto praticamente durante todo o período de nosso estudo. Frases imperativas como essa, têm como objetivo divulgar o leite em pó e persuadir as mães a introduzi-lo na alimentação infantil. Embora lembrem a filosofia higienista sobre o aleitamento materno que, segundo Almeida, ${ }^{28}$ "poderia ser resumida no seguinte lema: a saúde de seu filho depende de você. Amamente", elas têm um enfoque diferente. Enquanto o movimento higienista procurava estabelecer normas em relação à amamentação, fazendo com que as mulheres se sentissem responsabilizadas pela saúde de seus fillhos e culpadas, caso não as seguissem, nas peças publicitárias de leite em pó, a mensagem faz desaparecer o sentimento de culpa, tranqüilizando-as: "Você dá o que você tem de melhor a seus filhos". ${ }^{29} \mathrm{O}$ produto passa a representar os sentimentos e valores mais caros: "Leite Ninho: o melhor que você pode lhe dar", ${ }^{30}$ indispensável, pois é "puro e necessário como o seu amor". ${ }^{31}$ Como aponta Baudrillard, "a publicidade oferece tranqüilidade, já que sua função é gratificante e lúdica", ${ }^{32}$ não se apresenta como uma imagem negativa.

Por ser um leite integral e, portanto, destinado a qualquer faixa etária (com exceção dos primeiros seis meses, quando então deve ser diluído), a publicidade utilizou, como tema, crianças de todas as idades para divulgar o leite Ninho. Essas peças publicitárias, como outras de diferentes produtos e empresas, procuravam não destoar da política governamental.

O leite é considerado, pela população em geral, como um alimento completo, e essa idéia é transmitida em muitas publicações ou reportagens dirigidas às mães, como, por exemplo: "Não há nada mais completo: o leite é a maior fonte dos principais elementos nutritivos essenciais ao organismo" 33 ou "Alimento completo, o leite não pode deixar de estar presente em nosso processo de desenvolvimento". ${ }^{34}$

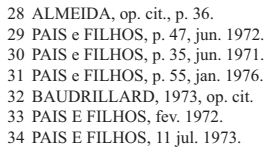


Para Barthes, a mitificação da pureza do leite é associada à da inocência infantil e considerada como uma garantia de força e vigor, ${ }^{35}$ o que pode ser traduzido pela mensagem "Ninho faz crianças saudáveis" e pela imagem de "pureza" formada pelo conjunto de objetos ou flores de cor branca presentes em muitas peças publicitárias do leite.

A questão da pureza está relacionada também com a higiene na produção do leite: a ordenha, a saúde dos animais, o transporte e o armazenamento predispõem o produto à contaminação e dificultam a conservação, enquanto as empresas possuem a tecnologia adequada para manter o leite, como explicita a mensagem, "fresco" e "puro". A propaganda chama também a atenção para o aspecto integral do leite, remetendo a uma preocupação da população em relação a diluição dos leites fluidos comercializados e à composição nutricional do produto.

Embora a recomendação médica de que o leite em pó utilizado na alimentação de lactentes fosse o "maternizado" ou "modificado", em razão de sua composição nutricional aproximar-se à do leite humano, a indústria, ao divulgar o leite em pó integral, não deixava clara essa diferença, o que poderia até induzir as mães menos informadas ao erro.

Com a mudança na percepção médica sobre o aleitamento materno, influenciada pelo marketing da indústria de alimentos infantis, o desmame tornou-se cada vez mais precoce e, além dos leites em pó modificados e do próprio leite integral para substituir o leite materno, as empresas começaram a produzir outros alimentos para serem introduzidos na alimentação do bebê.

Às vésperas do "Milagre Econômico", em 1968, a Nestlé lançou no Brasil sua linha de alimentos infantis, com "sopinhas e papinhas" prontas para servir. O momento, sem dúvida, foi oportuno, pois as inovações tecnológicas prometiam simplificar a vida da dona de casa, especialmente as da classe média e alta, que tiveram acesso aos mais diversos eletrodomésticos, que reduziram o tempo gasto com suas atividades domésticas. Para a mulher que, além da administração dessas atividades, preocupava-se com o preparo de refeições para filhos pequenos, encontrar essas preparações prontas foi um grande avanço.

Este estudo não teve como objetivo verificar a recepção da publicidade de alimentos infantis pelo leitor dessas revistas, especialmente pelas mães. Contudo, foi possível perceber que os apelos para o consumo dos produtos 
estiveram em sintonia com o momento histórico, político e cultural do período estudado e eram dirigidos à classe média da população. Apelos emocionais, científicos e culturais foram a tônica dos discursos publicitários analisados, muitas vezes afinados com a temática da propaganda governamental. Ao veicular imagens publicitárias, as empresas, além do próprio incentivo ao consumo, tentaram promover a interiorização, por parte dos consumidores, de normas e valores sociais, principalmente aqueles que o governo desejava alcançar.

Para conseguir seu objetivo, a indústria não somente fez uso de seu poder econômico, de seu conhecimento e tecnologia, de suas estratégias de marketing, como também apropriou-se do momento histórico, político e cultural por que passava a sociedade brasileira. Desse modo, pode-se afirmar que a indústria de alimentos, especialmente a Nestlé, promoveu a disseminação do aleitamento artificial com leite em pó, em detrimento do aleitamento materno, ao mesmo tempo em que introduziu novos hábitos alimentares por meio da difusão de alimentos complementares.

\section{Referências}

ALMEIDA, J. A. G. Amamentação: um híbrido natureza-cultura. Rio de Janeiro: Fiocruz, 1999.

ALVES, Paulo. Perspectivas acerca do método e técnica de análise dos discursos. História, São Paulo, v. 2, p. 33-37, 1983.

BARTHES, R. Mitologias. 3. ed. Rio de Janeiro: Difel, 1978.

BAUDRILLARD, J. A sociedade de consumo. Rio de janeiro: Edições 70, 1981.

BAUDRILlARD, J. O sistema dos objetos. São Paulo: Perspectiva, 1973. p. 149.

FICO, C. Reinventando o otimismo: ditadura, propaganda e imaginário social no Brasil. Rio de Janeiro: Fundação Getúlio Vargas, 1997.

FLANDRIN, J. L.; MONTANARI, M. História da alimentação. São Paulo: Estação Liberdade, 1996.

FOUCAULT, M. Microfisica do poder. 8. ed. São Paulo: Loyola, 1989.

MARQUES, M. B. Discursos médicos sobre seres frágeis. Rio de Janeiro: Fiocruz, 2000 . 
O CRUZEIRO, p. 132-138, 13 set. 1958.

O CRUZEIRO, p. 45-48, 5 ago. 1961.

O CRUZEIRO, p. 55, 28 jul. 1962.

PAIS E FILHOS, 11 jul. 1973.

PAIS E FILHOS, p. 19, set. 1968.

PAIS e FILHOS, p. 35, jun. 1971.

PAIS e FILHOS, p. 43, jun. 1971.

PAIS e FILHOS, p. 47, jun. 1972.

PAIS e FILHOS, p. 53, fev. 1971.

PAIS e FILHOS, p. 55, jan. 1976.

PIRATININGA, L. C. de. Publicidade: arte ou artifício? São Paulo: T. A. Queiróz, 1994.

SANTOS, C. R. A. dos. Por uma história da alimentação. História: Questões \& Debates, Curitiba, ano 14, n. 26-27, p. 156, 1997.

SOUZA, L. M. B. M.; ALMEIDA, J. A. G. História da alimentação do lactente no Brasil: do leite fraco à biologia da excepcionalidade. Rio de Janeiro: Revinter, 2005.

VEIGA, C. G.; GOUVEA, C. S. Comemorar a infância, celebrar qual criança? Festejos comemorativos nas primeiras décadas republicanas. Educação e Pesquisa, São Paulo, v. 26 , n. 1 , p. $140,2000$.

VEJA, 29 out. 1986, p. 102-103.

VESTERGAARD, T.; SCHRODER, K. A linguagem da propaganda. São Paulo: Martins Fontes, 1988. 